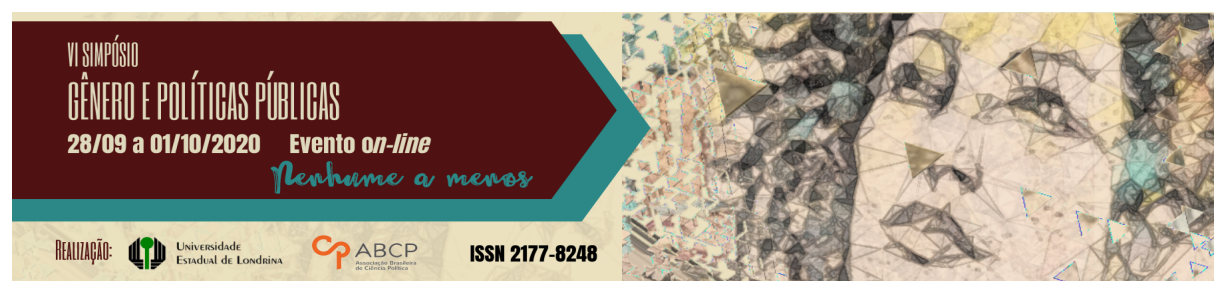

\title{
Assédio no mundo do trabalho e suas implicações para as mulheres na atualidade
}

\author{
Karoline Parrião Rodrigues"; Lorena Alves Silva²
}

\section{Resumo}

Propõe-se apresentação de resultados parciais de estudo acerca do assédio nas relações de trabalho, tendo como destaque as mulheres, pois acredita-se que essa é uma forma alarmante de violência, considerando os graves danos provocados à saúde física e mental da vítima, comprometendo sua vida em níveis pessoal, social e profissional. Trata-se de agressão que intenciona principalmente constranger, humilhar, obter vantagens pessoais, desestabilizar e/ ou desqualificar a vítima. O recorte de gênero faz-se necessário devido à sobrecarga de atividades para as mulheres, potencializada pela divisão sexual do trabalho, como também pelo reflexo da cultura machista e patriarcal ainda predominante. Outrossim, compreende-se que o sistema capitalista se apropria das relações desiguais para aprofundar a exploração da classe trabalhadora e com isso se fortalecer. Destarte, objetiva-se debater de que forma o assédio no trabalho manifesta-se para as mulheres atualmente e suas implicações para as vítimas, considerando os diversos aspectos de suas vidas.

Palavras-chave: assédio; trabalho; mulher.

\section{Harassment in the workplace and its implications for women nowadays}

\section{Abstract}

It is proposed to present partial results from a study about harassment in work relationships, focusing on women, because this seems to be an alarming way

1 Universidade Federal do Maranhão - UFMA; Assistente Social; Mestranda pelo Programa de Pós-Graduação em Políticas Públicas/ UFMA; kparriao@yahoo.com.br.

2 Universidade Federal do Maranhão - UFMA; Assistente Social; Mestranda pelo Programa de Pós-Graduação em Políticas Públicas/ UFMA; lorenalvesilva@bol.com.br.

GT 14 - Gênero, trabalho e sindicalismo 
of violence, taking into account the serious physical and mental health damages suffered by the victims, that compromise their personal, social and professional life. It is an aggression that mainly intends to embarrass, humiliate, obtain personal advantages, destabilize and/or disqualify the victim. The gender highlight is necessary due to the overload of activities for women, enhanced by the sexual division of labor, as well as by the reflection of the sexist/machist and patriarchal culture still predominant. Furthermore, it is understood that the capitalist system appropriates of these unequal relations in order to deepen the exploitation of the working class to strengthen itself. Thus, it is aimed to debate how harassment at the workplace manifests itself for women nowadays and its implications for victims, considering the several aspects of their lives.

Keywords: harassment; work; woman

\section{Mundo do trabalho e gênero: desigualdades persistentes}

Em recente publicação, o Fórum Econômico Mundial apresentou resultados do Relatório Mundial sobre a Desigualdade de Gênero de 20203, apontando que, em nível global, as desigualdades de gênero nas áreas da política, saúde, economia e educação serão eliminadas em 99,5 anos. De acordo com o levantamento, a desigualdade na área política diminuiu, embora ainda timidamente, porém, na área econômica as diferenças em desfavor das mulheres aumentaram de 57,8\% em 2018 para 58,1\% em 2019, tendo como principais fatores, segundo o referido relatório: persistência nos baixos níveis de mulheres em posições de liderança ou gestão, salários estagnados ou inferiores aos dos homens, precária participação no trabalho produtivo, baixos rendimentos e escolarização, entre outros.

Os dados acima são alarmantes e denunciam as diferenças abissais que permeiam a realidade assustadora das mulheres em todo o mundo, contexto no qual as desigualdades de gênero não podem ser dissociadas. Todavia, esse cenário resulta da formação social, cultural,

\footnotetext{
${ }^{3}$ Comunicado de imprensa do Word Economic Forum (À distância de mais do que uma vida: o mundo enfrenta uma espera de 100 anos pela paridade de gênero), publicado em 17 de dezembro de 2019 e disponível em: http://www3.weforum.org/docs/WEF_Global_Gender_Gap_Report_2020_Press_Rel ease_Portuguese.pdf
} 
política e econômica da maioria das sociedades, como a brasileira, permeada por relações patriarcais de poder, que enaltecem a figura do homem como ser dominante, capaz, produtivo, forte, viril e decisor. Os padrões que delineiam tais relações sociais objetificaram a mulher, a quem foi predestinado o cuidado e a manutenção da vida privada, que inclui família, maternidade, vida conjugal e atividades domésticas diversas, marcando claramente sua posição de inferioridade com relação aos homens.

Alinhado a esse pensamento, Antunes (2009) aponta que:

as relações entre gênero e classe nos permitem constatar que, no universo do mundo produtivo e reprodutivo, vivenciamos também a efetivação de uma construção social sexuada, na qual os homens e as mulheres que trabalham são, desde a infância e a escola, diferentemente qualificados e capacitados para o ingresso no mercado de trabalho. E o capitalismo tem sabido apropriar-se desigualmente dessa divisão sexual do trabalho (ANTUNES, 2009, p. 109).

Compreendemos que, para pensar as desigualdades de gênero, é imprescindível analisar o mundo do trabalho na sociedade capitalista, posto que a mulher historicamente ocupa espaço fundamental na alimentação dos sistemas econômicos, seja no trabalho reprodutivo gratuito ou não, seja no trabalho produtivo, alicerçado ainda pela divisão sexual do trabalho. Com base nisso, Amossé (2019), ao analisar estatísticas nos estudos europeus de gênero, identifica

a centralidade sempre atual do trabalho e do emprego na persistência das desigualdades de gênero: os progressos observados na escola e, às vezes, na esfera doméstica visivelmente não foram suficientes para modificar em profundidade os fatores de gênero do funcionamento da economia, que continuam a determinar os papeis sociais das mulheres e dos homens (AMOSSÉ, 2019, p. 45).

A centralidade do trabalho na vida humana justifica-se, não exclusivamente, pelo fato de que ele é inerente ao ser social, é intrínseco 
aos seres humanos, na medida em que realizam diversas atividades para satisfazer suas necessidades, em especial, as demandas relacionadas à sua sobrevivência, mas também à sua socialização, pois, corroborando com Ricardo Antunes (2006, p. 123), “o ato de produção e reprodução da vida humana realiza-se pelo trabalho. É a partir do trabalho, em sua cotidianidade, que o homem torna-se ser social, distinguindo-se de todas as formas não humanas". Assim, em cada momento histórico torna-se possível apreender como se estruturam concreta, objetiva e subjetivamente, a sociedade e os indivíduos por meio do trabalho.

Ponderando o aspecto político, Kergoat (2019, p. 288) assinala que "o trabalho é central porque é por meio dele que se organiza o exercício do poder em nossas sociedades", considerando-o uma atividade paradigmática. Assim, a autora acrescenta:

E o poder desse paradigma é tanto maior se consideramos o trabalho uma atividade que recobre tanto a esfera profissional quanto a esfera doméstica; consequentemente, a produção e a reprodução sociais são pensadas conjuntamente [...]. Utilizar o instrumento da divisão sexual do trabalho que pensa num continum o trabalho assalariado e o trabalho doméstico é a única maneira de levar em conta o conjunto do trabalho socialmente realizado, qualquer que seja seu local de prática, e seja ele gratuito ou remunerado (KERGOAT, 2019, p. 288-9).

A divisão sexual do trabalho, forma intencional de distribuição de tarefas e competências entre homens e mulheres, apresenta-se como uma potente estratégia capitalista de acumulação de riqueza e manutenção do status quo, materializada por meio do trabalho reprodutivo (em sua maioria gratuito), executado tradicionalmente por mulheres, mas também através das relações desiguais de poder entre homens e mulheres no trabalho produtivo (remunerado). De acordo com Kergoat (2009, p. 67), a denominada divisão sexual do trabalho possui dois princípios organizadores: “o da separação (existem 
trabalhos de homens e outros de mulheres) e o da hierarquização (um trabalho de homem 'vale' mais do que um de mulher)".

Engels (1984) a partir da sua celebrada obra "A origem da família, da propriedade privado e do Estado" contribui para a reflexão acerca dos antagonismos de classe historicamente representados pela dominação masculina sobre a mulher. À luz da análise do autor,

o primeiro antagonismo de classes que apareceu na história coincide com o desenvolvimento do antagonismo entre o homem e a mulher, na monogamia; e a primeira opressão de classes, com a opressão do sexo feminino pelo masculino. A monogamia foi um grande progresso histórico, mas, ao mesmo tempo, iniciou, juntamente com a escravidão e as riquezas privadas, aquele período, que dura até nossos dias, no qual cada progresso é simultaneamente um retrocesso relativo, e o bemestar e o desenvolvimento de uns se verificam às custas da dor e da repressão de outros (ENGELS, 1984, p.71).

Endossando o pensamento acima, Flávia Biroli (2016, p. 726) aponta que o "trabalho que as mulheres fornecem gratuitamente, como aquele que está envolvido na criação dos filhos e no cotidiano das atividades domésticas, libera os homens para que se engajem no trabalho remunerado", fato que possibilita aos mesmos, na lógica da sociedade capitalista, a manutenção e fortalecimento das suas posições de poder e domínio. Dessa forma, as relações hierárquicas de gênero, impostas pela construção social de padrões patriarcais, ultrapassam o âmbito privado/ doméstico e podem nitidamente ser identificadas nos espaços de trabalho produtivo sob a forma de diferenças salariais, dificuldade em ocupar cargos de chefia, necessidade de possuir maior escolarização e demonstrar maior competência, dificuldade de acesso à escolarização/ qualificação, imposição de tarefas consideradas femininas, desvalorização profissional, etc.

Ao aprofundar esse debate, a autora apresenta a divisão sexual do trabalho como lócus importante da produção de gênero, que não 
incide igualmente sobre todas as mulheres, atendendo uma dinâmica de classe. Dessa forma, Biroli (2018) parte de dois pressupostos:

O primeiro deles é que a divisão sexual do trabalho é uma base fundamental sobre a qual se assentam hierarquias de gênero nas sociedades contemporâneas, ativando restrições e desvantagens que modula as trajetórias das mulheres. O segundo pressuposto é que as hierarquias de gênero assumem formas diferenciadas segundo a posição de classe e raça das mulheres. A divisão sexual do trabalho, no entanto, não se detém nos limites das vantagens de classe e raça; impacta também as mulheres privilegiadas, porém com consequências distintas daquelas que se impõem à maioria das mulheres (BIROLI, 2018, p. 23).

As desigualdades no mundo do trabalho perpassam ainda a diversidade, subjetividade e identidade das mulheres, sendo necessário problematizar, indissociavelmente, as questões de gênero, classe e raça, pois se configuram como determinantes das vivências pessoais, sociais e profissionais das mulheres no mundo inteiro. Angela Davis (2019) ajuda-nos a refletir sobre as desigualdades entre mulheres garantindo que

quando estudamos o papel do gênero na esfera econômica, é essencial reconhecer que o gênero é sempre também uma questão de classe e de raça. $\mathrm{O}$ valor heurístico do que chamamos de 'intersecionalidade' não poderia ser subestimado. Se podemos celebrar as espetaculares transformações do trabalho das mulheres ao longo dos últimos 50 anos, a relegação do trabalho doméstico à margem de nossas preocupações com a atividade econômica das mulheres é atravessada por estruturas ao mesmo tempo históricas e contemporâneas de xenofobia, de racismo e de heteropatriarcado (DAVIS, 2019, p. 212).

Dessa maneira, importa delimitar que, mediante um conjunto de mediações, é por meio do trabalho que se desencadeia a reprodução social e, simultaneamente, se reproduzem também as relações de gênero 
e as individualidades. Ao estudar a categoria trabalho nas particularidades da sociedade capitalista Cisne; Santos (2018) apontam:

Nesse processo, buscaremos o entendimento da diversidade humana que é central para apreensão das expressões concretas dessa diversidade, a exemplo da vida das mulheres, da população negra e LGBT, considerando as particularidades oriundas da dimensão ético-racial, das lutas sociais contra o racismo, o patriarcado e o heterossexismo (CISNE; SANTOS, 2018, p. 28).

É mister analisar as estruturas sociais, econômicas e culturais que determinam as vivências das mulheres. Os avanços alcançados pelas conquistas feministas no mundo inteiro, especialmente a partir do século XIX, no que tange à liberdade, direitos civis, sexuais e trabalhistas são indiscutíveis. Entretanto, os ganhos da luta por equidade de gênero não foram, e ainda não são, desfrutados igualmente por todas as mulheres. As discriminações de classe, gênero e raça continuam atingindo predominantemente mulheres negras, indígenas, imigrantes, $\mathrm{LGBT}_{+}$e refugiadas. Nesse aspecto, Antunes (2020) analisa a realidade brasileira:

Dada a divisão sociossexual e racial do trabalho em sua nova morfologia, as mulheres trabalhadoras brancas sofrem mais que os homens brancos [...] enquanto as trabalhadoras negras são ainda mais penalizadas que as brancas (veja-se o exemplo das trabalhadoras domésticas no Brasil, que totalizam 6,2 milhões, das quais 68\% são negras) (ANTUNES, 2020).

Diante do exposto, podemos identificar que o modo de produção capitalista acirra as desigualdades sociais, de gênero, econômicas e culturais, dividindo e enfraquecendo a classe trabalhadora com vistas à sua manutenção e fortalecimento. Sob essa lógica, Freitas; Heloani; Barreto (2008, p. 12) refletem acerca do modo pelo qual o trabalho encontra-se organizado na atualidade e como as 
formas assumidas pelo sistema econômico favorecem relações de trabalho violentas, posto que

A rentabilização do ser humano, ou seja, a sua transformação em coisa, em projeto ou em capital permite uma justificativa da violência no ambiente do trabalho e neutraliza o mote da sobrevivência e do vale-tudo para se salvar, deixando um rastro de estigmatizados como perdedores e descartáveis.

Compreendemos que o acirramento dessas relações de trabalho conflituosas, fortalecidas pelos antagonismos de classe, culmina em situações diversas de violência. Entretanto, o controle e imposição de poder que permeiam essas relações são alimentados e materializados pela herança machista do patriarcado, vitimando a mulher - negra, trans, indígena, imigrante, etc. - diariamente nos mais variados espaços de sua vivência, tanto no âmbito privado como público, como também provocando consequências graves para as vítimas e a sociedade, a exemplo dos assédios moral e sexual ocorridos nas relações de trabalho.

\section{O assédio na perspectiva das relações de trabalho da mulher}

Neste estudo, assumimos a perspectiva de que o trabalho é uma categoria central para analisar as relações de gênero e suas persistentes desigualdades, visto que se encontra indissociado das relações de poder, dominação e opressão predominantes na sociedade capitalista aqui em análise. Deste modo, precisamos analisar as relações de trabalho das mulheres considerando as mais variadas formas de discriminação, opressão, exploração, violência e desigualdades a que estão expostas historicamente.

A violência no mundo do trabalho perpassa diversas épocas e sistema econômicos, no entanto, destaca-se o assédio como uma forma atual de violência, que acompanha as reconfigurações do mundo do trabalho na atualidade. Faz-se necessário evidenciar que o sistema capitalista, somado às políticas neoliberais em curso provocam estratégias de precarização generalizada do trabalho, tais como: 
sucateamento dos sistemas de proteção social; flexibilização das relações de trabalho; ameaça aos direitos trabalhistas; gerencialismo, inclusive no serviço público; individualismo e competitividade; redução do trabalho formal e ampliação do informal; enfraquecimento dos laços de solidariedade, etc. Acreditamos que esses elementos provocam relações de trabalho cada vez menos saudáveis, contribuindo com a incidência de violências, como o assédio.

A partir disso, é imprescindível elucidar as formas, motivações e consequências do assédio nas relações de trabalhado das mulheres por compreendê-lo como uma das manifestações de violência que assombra o cotidiano feminino. Segundo os estudos de Freitas, Heloani e Barreto (2008), essa violência não é abstrata,

ela é um processo objetivo entre atores objetivos e deixa consequências explícitas, ainda que, no mundo atual, o trabalho esteja se transformando em algo precário e com ritmo intensificado, a banalização da violência pareça não deixar espaço para nenhuma gramática de construção de diálogo, visto que cada um está ocupado com a própria sobrevivência (FREITAS; HELOANI; BARRETO, 2008, p. 36).

Marie-France Hirigoyen, considerada internacionalmente como uma das pioneiras nos estudos sobre assédio, caracteriza-o como "a violência perversa no cotidiano" dado seu alto poder destrutivo não somente para as vítimas. A pesquisadora concluiu que o assédio moral pode ser "definido como qualquer conduta abusiva (gesto, palavra, comportamento, atitude ...) que atente, por sua repetição ou sistematização, contra a dignidade ou integridade psíquica ou física de uma pessoa, ameaçando seu emprego ou degradando o clima de trabalho" (HIRIGOYEN, 2011, p. 17)

O assédio moral e/ ou sexual ocorre independente do grau de hierarquia, podendo ser provocado por parte da chefia, de colegas ou de subordinado/a contra chefia, sendo mais frequente a ocorrência vertical descendente - quando praticado da chefia para o /a subordinado/ a. 
Evidenciando as análises de Hirigoyen (2002), Freitas, Heloani e Barreto (2008) e Figueredo (2012), o assédio moral possui algumas características, tais como: a degradação intencional do ambiente de trabalho; desqualificação do trabalho da vítima; ataques contra a dignidade e idoneidade da pessoa; provocação de situações de constrangimento, humilhação, injúria e exposição; condução de situações que causem o isolamento da vítima; além de ameaça à segurança da vítima com agressões verbais, físicas e/ ou sexuais, para citar algumas. No entanto, Freitas, Heloani e Barreto (2008, p. 33) ressaltam que "esses comportamentos, repetitivos e frequentes, podem ser justapostos, portanto, o agressor pode lançar mão de diversos tipos simultaneamente, o que torna o ataque muito mais poderoso e rápido no seu intento de destruir o outro"

De outra forma, evidenciando o assédio sexual, podemos identificá-lo através de comentários constrangedores e/ ou maliciosos, elogios excessivos - principalmente aos atributos físicos, toques e convites obscenos, piadas de cunho erótico, contatos físicos indiscretos e maliciosos, sexualização da vítima em redes sociais, etc. São comportamentos e/ ou atitudes que visam obter vantagens, chantagear ou negociar algo com a vítima, imprimindo correlação de força e poder contra sua vontade. Margarida Barreto (2006) concluiu, como resultado de sua pesquisa, que o assédio sexual encontra-se

presente nas relações hierárquicas assimétricas de poder. Incomoda as mulheres, interfere as relações entre os pares, degrada as condições de trabalho e é considerado vexatório por elas, criando um ambiente hostil e de intimidação. Segundo o relato das trabalhadoras, o assédio sexual se manifesta em contato físico indesejável, insinuações e piadas grosseiras, comentários jocosos e burlescos, ameaças, fofocas, maledicências, ironias e exibição de material pornográfico associados a promessas de promoção profissional (BARRETO, 2006, p. 138).

Compreendendo que as mulheres são as maiores vítimas de assédio moral e sexual, dadas as implicações das desigualdades de 
gênero em todos os espaços onde estão presentes, destacamos as contribuições de Hirigoyen (2011) que realizou valioso estudo acerca do assédio moral em países variados. A pesquisadora identificou que 70\% das vítimas são mulheres, contrapondo os 30\% de homens. A maioria dos assédios é procedente do superior hierárquico, somando $58 \%$ dos casos. Considerando as consequências sociais e econômicas, em 36\% dos casos houve saída do trabalho, em $20 \%$ a pessoa foi demitida por falha, em $9 \%$ a demissão foi negociada, em $7 \%$ a pessoa pediu demissão e houve $1 \%$ de casos de aposentadoria. O levantamento mostrou ainda equiparação de $50 \%$ para casos do setor privado e $50 \%$ do setor público, embora haja diferença nas formas de ocorrência do assédio em cada setor.

O assédio, na perspectiva das relações de trabalho das mulheres, igualmente às demais formas de violência a que são submetidas, provoca consequências diversas para as vítimas, envolvendo os mais diversos âmbitos de suas vidas. Patrícia Figueredo (2012), com base em Hirigoyen, contribui para a compreensão das implicações do assédio considerando os âmbitos individual, organizacional e social, com ênfase para a identificação de: desenvolvimento de transtornos mentais (depressão, ansiedade, transtornos alimentares, comportamentos autodestrutivos e suicídio); comprometimento da saúde física; isolamento social; queda na produtividade e no rendimento não somente da vítima, mas também da equipe; relacionamento conflitivo entre o grupo de trabalho; falhas no processo de comunicação institucional; afastamento das vítimas por motivo de doença e até demissão com ônus para o órgão/ empresa; aumento das taxas de desemprego, assim como das aposentadorias precoces; maior dependência de políticas públicas; acirramento das desigualdades sociais e consequente fortalecimento do sistema de produção/ reprodução capitalista.

Notamos, com isso, o quão grave as implicações do assédio moral e/ou sexual podem se apresentar. Contudo, as legislações brasileiras pertinentes ao tema são terrivelmente tímidas, a exemplo do 
Projeto de Lei $\mathrm{N}^{\mathrm{o}}$ 4.742, que propõe alterações no Código Penal Brasileiro com a inclusão da tipificação do assédio como crime, em tramitação desde 2001. De outra forma, há esforços institucionais quanto à prevenção do assédio em órgãos públicos e ambientes empresariais, como também jurisprudências reconhecendo o assédio como violência relacionada ao trabalho.

Importante vitória para a classe trabalhadora foi a realização do $1^{\mathrm{o}}$ Tratado Internacional sobre violência no trabalho, a chamada Convenção para Eliminação da Violência e do Assédio no Mundo do Trabalho - C190, por intermédio da Organização Internacional do Trabalho - OIT, em Genebra - Suíça, dia 21 de junho de 2019. A C190 visa fortalecer a luta em defesa do trabalho decente para todos os trabalhadores e trabalhadoras, com especial recorte para a violência com base no gênero, reconhecendo o assédio como uma violência que perpassa o mundo do trabalho, ameaçando os direitos humanos, a dignidade e a igualdade de oportunidades. Ressaltamos que, apesar do grande avanço proposto pela referida legislação, a C190 ainda possui pouca adesão dos países membros da OIT.

Conforme anunciado, a história das mulheres foi construída sob fortes elementos de exploração, opressão, desigualdades, preconceitos e discriminações de diversas ordens, atingindo de maneiras diferentes cada uma, a depender dos aspectos relativos à intersecionalidade, como classe, gênero e raça. Em se tratando das relações de trabalho, as configurações tradicionais de hierarquia e disputa de poder permanecem atuais, embora as conquistas feministas tenham rompido inúmeras barreiras. Entretanto, faz-se necessário o enfrentamento constante de todo tipo de opressão e segregação, quer seja no âmbito privado ou no público.

\section{Conclusões}

Retomamos a conclusão do Fórum Econômico Mundial, que aponta o marco de quase 100 anos para o mundo conseguir equiparar 
as desigualdades de gênero, de forma a ilustrar o quão perversas e persistentes essas desigualdades têm se estruturado em nossa sociedade. Reconhecendo as imensas e inúmeras conquistas alcançadas pelas mulheres em todo o mundo, que demandaram muita luta, resistência e abdicação, causa espanto tamanha revelação. Nota-se que a cultura machista do patriarcado alicerça as desigualdades de gênero provocando diversas formas de violência nos mais variados espaços de vivência das mulheres, tanto privados, quanto públicos, onde o homem ainda se sobrepõe.

As mulheres do século XXI ainda lutam em seu cotidiano contra a objetificação, opressão, discriminação, exploração e desigualdades diversas. Essa mesma mulher é condicionada a acumular jornadas de trabalho produtivo e reprodutivo (remunerado ou não) simultaneamente com a luta por condições objetivas de vida que possibilitem sua emancipação. Dessa forma, os movimentos feministas em sua historicidade e contradições, foram determinantes para problematizar as desigualdades de gênero e relações hierárquicas de poder, permitindo às mulheres ampliarem sua percepção enquanto sujeito de direitos. Esse despertar exige a ruptura com as mais variadas formas de apropriação e alienação decorrentes dessas relações, especialmente a ruptura com a naturalização da subserviência. Assim, é possível chegar à dimensão coletiva da consciência de classe, determinante para construção de uma outra sociabilidade.

É necessário compreender como o machismo, estrutural e enraizado na sociedade patriarcal dominante até os dias de hoje, além de fortemente estimulado pelo modo de produção capitalista, conduz as relações sociais e permeia todas as esferas de vida das mulheres em suas múltiplas identidades e diversidade. $\mathrm{O}$ resultado dessas relações desiguais de gênero é a insegurança generalizada das mulheres, visto que ainda prevalecem as relações hierárquicas de poder em que o masculino sobrepõe-se ao feminino.

Dessa forma, o mundo do trabalho é igualmente afetado por tais relações conflituosas e danosas, possibilitando a prática de assédio, aqui 
considerado como violência que possui o recorte de gênero indispensável. Consideramos que as desigualdades de gênero, fortemente espelhadas na divisão sexual do trabalho, aliadas à precarização e reconfiguração das relações de trabalho contribuem para a ocorrência do assédio no ambiente de trabalho. Assim, as reflexões aqui apresentadas sinalizam a relevância do tema para a sociedade, posto que as implicações do assédio podem ser graves, irreversíveis e afetam a todos/as os/as envolvidos/as - vítima, família, empresa/ instituição, Estado, etc.

Mediante o exposto, acreditamos ser primordial que as instituições brasileiras dispensem esforços enérgicos no enfrentamento ao assédio moral e/ ou sexual decorrente das relações de trabalho. A ausência ou insuficiência de políticas e/ ou espaços de enfrentamento, acolhimento e atendimento ao assédio colabora com a reprodução de tais práticas, inibindo e encarcerando as vítimas, como também fortalecendo o agressor, em sua maioria homem. É fundamental que o país avance no aparato legislativo, ratifique a C190, mas também promova políticas públicas que garantam condições objetivas de vida com segurança para mulheres - saúde, educação, emprego/ renda, creche, habitação, etc., de forma a promover equidade com relação aos homens, mas não somente, também entre as próprias mulheres.

Nota-se que essa demanda social, por mais perversa que seja, ainda não possui espaço prioritário na agenda governamental. É necessário o fortalecimento dos espaços de luta e representação dos/as trabalhadores/as diante de tantos retrocessos na garantia dos direitos sociais e trabalhistas diretamente vinculados ao avanço das políticas neoliberais e ultraconservadoras nos últimos anos no Brasil.

Destarte, é imperativo frisar que o aprofundamento das diferenças culturais, sociais, econômicas e de gênero divide a classe trabalhadora, favorecendo assim o fortalecimento dos processos de exploração, dominação, opressão e acumulação do sistema capitalista. Nesse sentido, para transformar as práticas e relações sociais que estão postas, é urgente superar as diferenças, sejam elas de gênero, cultural, 
religiosa ou étnica, respeitando a diversidade e unicidade peculiar a cada ser social, devendo ser eliminada qualquer forma de machismo e segregação. Tal caminho nos leva para a consequente superação do sistema econômico em curso, visto que o capitalismo potencializa e torna persistente tais relações sociais perversas.

\section{Referências}

À distância de mais do que uma vida: o mundo enfrenta uma espera de 100 anos pela paridade de gênero. Word Economic Forum, Genebra, Suíça, 17 de dezembro de 2019. Disponível em: http://www3.weforum.org/docs/WEF_Global_Gender_Gap_Repor t_2020_Press_Release_Portuguese.pdf

AMOSSÉ, Thomas. As estatísticas nos estudos de gênero: um instrumento revelador? In: MARUANI, Margaret, (Org.). Trabalho, logo existo: perspectivas feministas. Rio de Janeiro: FGV Editora, 2019.

ANTUNES, Ricardo. Adeus ao trabalho? Ensaio sobre as metamorfoses e a centralidade do mundo do trabalho. 11. ed. São Paulo: Cortez, 2006.

ANTUNES, Ricardo. Coronavírus: o trabalho sob fogo cruzado. São Paulo: Cortez, 2020. E-book.

ANTUNES, Ricardo. Os sentidos do trabalho: ensaio sobre a afirmação e a negação do trabalho. 2. ed. São Paulo: Boitempo, 2009.

BARRETO, Margarida Maria Silveira. Violência, saúde e trabalho: uma jornada de humilhações. São Paulo: EDCU, 2006.

BIROLI, Flávia. Divisão sexual do trabalho e democracia. DADOS Revista de Ciências Sociais, Rio de Janeiro, v. 59, n. 3, p. 719-681, 2016.

BIROLI, Flávia. Gênero e desigualdades: os limites da democracia no Brasil. 1. ed. São Paulo: Boitempo, 2018.

CISNE, Mirla; SANTOS, Silvana Mara Morais dos. Feminismo, diversidade sexual e serviço social. São Paulo: Cortez, 2018.

DAVIS, Angela. Mulheres, raças, classes: desafios para o século XXI. In: MARUANI, Margaret (Org.). Trabalho, logo existo: perspectivas feministas. Rio de Janeiro: FGV Editora, 2019. 
ENGELS, Friedrich. A origem da família, da propriedade privada e do Estado. Rio de Janeiro: Civilização Brasileira, 1984.

FIGUEREDO, Patrícia Maria. Assédio moral contra mulheres nas organizações. São Paulo: Cortez, 2012.

FREITAS, M. E. de; HELOANI, J. R.; BARRETO, M. Assédio Moral no Trabalho. São Paulo: Cengage Learning, 2008.

HIRIGOYEN, Marie-France. Assédio Moral: a violência perversa do cotidiano. 5. ed. Rio de Janeiro: Bertrand Brasil, 2002.

HIRIGOYEN, Marie-France. Mal-estar no trabalho: redefinindo o assédio moral. 6. ed. Rio de Janeiro: Bertrand Brasil, 2011.

KERGOAT, D. Divisão sexual do trabalho e relações sociais de sexo. In: HIRATA, H. et al. (Org.). Dicionário crítico do feminismo. São Paulo, SP: UNESP, 2009.

KERGOAT, D. O trabalho, um conceito central para os estudos de gênero? In: MARUANI, Margaret (Org.). Trabalho, logo existo: perspectivas feministas. Rio de Janeiro: FGV Editora, 2019. 